\title{
Resúmenes en Congresos y Publicaciones. Una tarea aún pendiente
}

Sra. Editora:

Quisiera hacer llegar a Ud., algunos comentarios en relación a los resúmenes presentados en los Congresos, en este caso aquellos de nuestro Congreso, aunque los comentarios también pudiesen alcanzar a otras especialidades.

A través de los años, no más del 10\% de los resúmenes presentados terminan en una publicación. Esa fue la regla mientras fui editor, y sospecho que eso no ha cambiado. Pese a solicitarlo personalmente por todos los editores que continuaron, el éxito ha sido siempre discreto.

El 10\% de trabajos publicados, generalmente, corresponden a colegas con líneas de investigación muy establecidas. La mayor parte de estos manuscritos se envían a revistas indexadas y con factores de impacto razonablemente alto. Esto tiene una razón de ser. Las revistas indexadas son importantes para los autores por razones curriculares. Un porcentaje muy pequeño, aunque siempre importantes de ese grupo se publica en Chile.

Entiendo los trabajos presentados en los Congresos como fruto de una actividad de investigación (básica o clínica), investigación que representa líneas de trabajos personales o grupales, o representan esfuerzos "personales" cuyo propósito es contribuir con ideas, casos clínicos, revisiones u otros, generalmente derivados de la práctica clínica.

Los resúmenes presentados a un Congreso, son solo eso "resúmenes". Utilidad muy poca y cero impacto desde el punto de vista curricular. No se consideran como publicaciones a menos que estén inextenso en alguna revista. can?

La pregunta, por lo tanto, es ¿por qué no se publi-

Sin tener todas las respuestas, podría solo aventu- rarme:

- La finalidad del trabajo es solo presentarla a un Congreso.

- El trabajo pudiese tener problemas, por lo tanto, no me quiero someter a la revisión de mis pares. No me gusta que mi escrito sea rechazado o deba ser modificado.

- Sin tener los conocimientos (todos partimos igual) no pedimos ayuda a aquellos que tienen experiencia.

- Dos situaciones extras, que ya las he mencionado previamente. El uso y abuso de bases de datos, donde se puede obtener cualquier cosa, y finalmente, los compromisos con la industria farmacéutica, poco dispuestos a aceptar resultados acordes a sus deseos.

Si no sabemos o nos cuesta escribir este tipo de trabajo, pidamos ayuda. Hay colegas en cada centro dispuestos a enseñar el bonito arte de terminar con una publicación inextenso un trabajo de investigación.

Por lo tanto, mensaje a nuestros investigadores profesionales... Cortínez... Penna... Torres... Sepúlveda, solo por mencionar a algunos. Por favor aportemos a nuestra Revista. Es un canal de comunicación y docencia importante para los anestesiólogos y no anestesiólogos del país, y una manera muy importante que la Revista alcance niveles de citación que nos permita, mejorar nuestra indexación.

Dr. Guillermo Lema

División de Anestesiología

Facultad de Medicina

Pontificia Universidad Católica de Chile 